\title{
Effect of Probiotic, Prebiotic and Synbiotic Supplementation on Haematological and Serum Biochemical Profiles in Murrah Buffalo Calves
}

\author{
M. Sri Lekha*, Ch. Venkata Seshaiah, P. Ashalatha and K. Raja Kishore \\ Department of Livestock Production Management, NTR College of Veterinary Science, \\ Gannavaram, Andhra Pradesh 521101, India \\ *Corresponding author
}

\section{A B S T R A C T}

\section{Keywords}

Murrah buffalo calves,

haematological, serum biochemical parameters, supplementation

Article Info

Accepted:

12 April 2021

Available Online:

10 May 2021
Twenty four Murrah buffalo calves of about six months age were randomly divided into four groups of six calves each on the basis of body weight (BW) in a completely randomized design (CRD). Group I is control (C), Group-II was supplemented with multistrain probiotic containing 7 bacterial strains and 2 yeast strains $\left(2 \times 10^{9} \mathrm{cfu} / \mathrm{gm}\right)$ at $5 \mathrm{gm} / \mathrm{calf} / \mathrm{day}(\mathrm{T} 1)$. Group-III was supplemented with prebiotic Mannonoligosaccharide + inulin at $5 \mathrm{gm} / \mathrm{calf} /$ day (T2) and Group-IV was supplemented with synbiotic containing multistrain probiotic at $2.5 \mathrm{gm}$ and $2.5 \mathrm{gms}$ of prebiotic Mannonoligosaccharide + inulin per calf/day (T3) for a period of 90 days. The results showed no significant difference in haematological and serum biochemical parameters among the treatment and control groups. However, from $60^{\text {th }}$ day onwards, significantly $(\mathrm{P}<0.05)$ lower levels of serum cholesterol was observed in T1, T2 and T3 groups compared to the control. In conclusion, the dietary supplementation of the above said probiotic, prebiotic and synbiotics have no effect on haematological and serum biochemical values in in buffalo calves.

\section{Introduction}

Buffalo is the back bone of Indian dairy industry, however, the mortality rate in buffalo calves particularly during first few months of their postnatal life is high, predominantly due to calf scores, causing heavy loss to the buffalo producers in India. Therefore, to combat infection, antibiotics are commonly being used as feed additives in the rations of calves. However indiscriminate and subtherapeutic levels of antibiotics usage in calves results in development of drug-resistant microorganisms which are responsible for treatment failures (Jin et al., 1997).

In an effort to replace antibiotics in animal feeds, Probiotic, prebiotics and combination of 
probiotic and prebiotic (synbiotics) have been proposed as alternates to antibiotics. (Heinrichs et al., 2003; Morill et al., 1995. Probiotics are live microbial feed supplements which beneficially affect the host animal by improving its microbial balance (Fuller, 1989). Rolfe (2000) suggested that multistrain probiotic may be more useful than a single strain because they can proliferate more lactic acid bacteria than single strain probiotic. Prebiotics are non-digestible carbohydrates which are not metabolized in the small intestine and fermented in large intestine. Oligosaccharides such as fructooligosaccharide (FOS), galactooligosaccharide (GOS), and mannanoligosaccharide (MOS) are among the most important prebiotics that have been studied as alternatives to antibiotics. Recently, prebiotics have been shown to have immune-enhancing characteristics (Okomato et al., 2003; Fleige et al., 2009). Synbiotics are dietary supplements combining both prebiotics and probiotics in a form of synergism that beneficially affects the host by improving the survival and implantation of microbial dietary supplements in the gastrointestinal tract, by selectively stimulating the growth and/or by activating the metabolism of health-promoting bacteria, and thus improving host welfare. However, very scanty information is available on comparative study of benefits of probiotics, prebiotics and synbiotics in buffalo calves. So, this study was taken up to investigate the changes in haematological and serum biochemical parameters upon dietary supplementation of probiotics, prebiotics and synbiotics in buffalo calves.

\section{Materials and Methods}

Twenty four Murrah buffalo calves of approximately 6 months age were selected from LFC, NTR College of Veterinary Science, Gannavaram and divided into four groups of six calves each on the basis of body weight (BW) in a completely randomized design (CRD). The average body weight (kg) in each of the groups was similar before the start of the experiment. All the experimental calves were housed in a well protected animal shed with good ventilation and provision for individual feeding and watering. All the calves were fed with Hybrid Napier green fodder and concentrate mixture as basal diet as per their nutrient requirements (ICAR 2013). The calves were divided into four groups i.e. Group I is control, Group-II was supplemented with multistrain probiotic containing 7 bacterial strains and 2 yeast strains $\left(2 \times 10^{9} \quad \mathrm{cfu} / \mathrm{gm}\right) @ 5 \mathrm{gm} / \mathrm{calf} /$ day. Group-III was supplemented with prebiotic Mannon oligosaccharide + Inulin @ $5 \mathrm{gm} /$ calf/day and Group-IV was supplemented with synbiotic containing multistrain probiotic @ $2.5 \mathrm{gm}$ and $2.5 \mathrm{gms}$ of prebiotic Mannon oligosaccharide + Inulin per calf/day for a period of 90 days. All the experimental calves were identified using ear tags. Deworming and deticking was done using Fenbendazole @ $10 \mathrm{mg} / \mathrm{kg} \mathrm{BW}$ and Deltamethrin @ 4ml/L before the start of the experiment. All the calves were allowed to have adaptation period for 15 days before the actual trail, during which they were fed with basal diet. After the adaptation period calves were fed with their respective treatment diets for 90 days. The diet of the experimental animals included chopped Hybrid Napier as roughage source and concentrate mixture. Feeding of concentrates followed by fodder was done daily in the morning and evening at a fixed time. Feed offered and feed left in the individual mangers were noted to obtain feed intake of the calf. The leftover concentrate mixture, if any was weighed.

Two blood samples from each calf were collected aseptically at fortnightly intervals before morning feeding via a single jugular vein puncture with the help of sterilized needles. One sample was collected in EDTA 
vacuutainer (AcCuvet-PLUS) for haematological analysis and the other sample was collected into an anti-coagulant free centrifuge tube (Tarsons) to obtain serum. Whole blood was collected into EDTA vacuutainer for analysis of haematological constituents like haemoglobin (Hb), RBC, WBC, PCV using automatic haematology analyser (Mindray BC-2800). Serum samples were obtained after centrifuging whole blood at $2000 \mathrm{x} \mathrm{g}$ for $10 \mathrm{~min} ; 4^{\circ} \mathrm{C}$ in refrigerated centrifuge (Thermo Fisher scientific). The serum so obtained was collected into eppendorf tubes. Serum stored in eppendorf tubes was analysed for serum glucose, total protein (TP), albumin, globulin, cholesterol. The commercially available kits procured from Coral Clinical System-Tulip Diagnostics India were used for assessment of glucose, total protein, albumin, globulin, cholesterol. The concentrations of the said biochemical parameters in serum were determined using a spectrophotometer (Thermo fisher scientificMultiskan® Go). The analysis was carried out according to the manufacturer's recommendations. The data obtained was analyzed according to statistic computer program SPSS version (15.01) (SPSS, 2006). The data pertaining to hematological and serum biochemical profiles were analyzed using ANOVA and Post-hoc tests.

\section{Results and Discussion}

\section{Heamotological parameters}

\section{Heamoglobin}

The results on the effect of dietary supplementation of synbiotics on haemoglobin $\mathrm{Hb}$ ) concentration in Murrrah calves are represented in the Table 1. The $\mathrm{Hb}$ concentration was within the normal range in all the experimental calves. Statistical analysis revealed that there was no significant difference observed among the groups throughout the experimental study. Present results were consistent with the findings of Kim et al., (2011) who observed no significant effect on hemoglobin levels in Holstein calves supplemented with probiotics. Contrary to the present results, Dar et al., (2017) observed increased $\mathrm{Hb}$ concentration in calves supplemented with probiotic, prebiotic and synbiotic compared to the control.

\section{Total erythrocyte count}

The effect of probiotic, prebiotic and synbiotic supplementation on total erythrocyte count in Murrah calves is represented in the Table 1. The results revealed no significant difference in total erythrocyte count among the treatment and control groups which was in conformity with the results of Kim et al., (2011) and Dimova et al., (2013) who reported that erythrocyte count remained unaffected by probiotic supplementation in calves. Dar et al., (2017) and Adams et al., (2008) also reported no significant effect of probiotic supplementation on erythrocyte count. Contrary to the present findings, Abdel-Fattah and Fararh (2009) observed a significant increase in RBC when broiler chicks were supplemented with probiotics, prebiotics and synbiotics.

\section{Total leucocyte count}

The effect of probiotic, prebiotic and synbiotic supplementation on total leucocyte count in Murrah calves is represented in the Table 1. The results of the present study indicates that there was no statistically significant difference in total leucocyte count among the groups upon supplementation of probiotics, prebiotics and synbiotics in Murrah calves. Chen et al., (2005) and Agazzi et al., (2014) also reported that there was no effect of supplementing probiotic on white blood cell count of growing pigs and calves, respectively. Contrary to the present findings, Dar et al., (2017) reported 
that supplementation of probiotics, prebiotics and synbiotics in calves significantly $(\mathrm{P}<0.05)$ increased total leucocyte count compared to the control. Al-Siaidy et al., (2010) also reported significantly higher white blood cell count in calves fed with both commercial grade and culture of Lactobacillus acidophilus than control group.

\section{Packed cell volume}

The effect of probiotic, prebiotic and synbiotic supplementation on packed cell volume (PCV $\%)$ in Murrah calves is represented in the Table 1. The results revealed no significant difference in PCV among the treatment and control groups. The present results were consistent with the findings of Kim et al., (2011) who observed no significant difference between probiotic supplemented group and antibiotic treated group in Holstein calves. Similarly no significant effect was observed by Gazanfar et al., (2015) on packed cell volume values by probiotic supplementation in dairy heifers. Contrary to the present findings, Dar et al., (2017) reported that supplementation of probiotics, prebiotics and synbiotics in calves significantly $(\mathrm{P}<0.05)$ increased PCV compared to the control.

\section{Serum biochemical profiles}

\section{Serum glucose level}

The effect of probiotic, prebiotic and synbiotic supplementation on serum glucose level in Murrah calves is represented in the Table 2. Statistical analysis revealed that there was no significant difference in the serum glucose levels among the treatments. The present results were consistent with the findings of Dar et al., (2017) who reported non-significant difference in glucose levels in probiotic, prebiotic and synbiotic supplemented calves throughout the experimental period. The results were in accordance with the findings of Adams et al., (2008) and Frizzo et al., (2010) who reported no significant difference in serum glucose levels in probiotic and control group calves. Further, Rekiel et al., (2007) and Silva et al., (2012) reported that prebiotic supplementation had no effect on plasma glucose levels in pigs and calves respectively. Gujar (2017) also reported no significant difference in the serum glucose levels among probiotic, prebiotic and synbiotic supplementation in Sahiwal cattle compared to the control group cattle. Chaudhary et al., (2008) reported that the dietary supplementation of direct fed microbial had no significant effect on serum glucose levels of crossbred cattle calves. Similar to the present findings El-Din (2015), also reported no significant effects of probiotic on serum glucose levels in cows.

\section{Albumin}

The effect of probiotic, prebiotic and synbiotic supplementation on albumin level in Murrah calves is represented in the Table 2. The results revealed that there was no significant difference in the albumin levels among treatments which were in agreement with the findings of Galip (2006) who observed that the albumin concentration was not significantly modified in rams supplemented with yeast. Chaudhary et al., (2008) also observed no significant effect on albumin concentration in crossbred cattle calves when supplemented with direct fed microbials.

\section{Globulin}

The effect of probiotic, prebiotic and synbiotic supplementation on serum globulin levels in Murrah calves is represented in the Table 2.

Statistical analysis revealed that there was no significant difference in the serum globulin levels among the groups. In accordance to the present study Galip (2006) observed that the dietary supplemental yeast has no effect on serum globulin concentration in rams. 
Table.1 Effect of probiotic, prebiotic and symbiotic supplementation on haematological profiles in murrah calves

\begin{tabular}{|c|c|c|c|c|c|}
\hline Parameters & Days & $\mathbf{C}$ & $\mathbf{T}-1$ & T- 2 & T-3 \\
\hline \multirow{2}{*}{ Hb $(\mathbf{g} / \mathbf{d L})$} & $0^{\text {th }}$ Day & $9.80 \pm 0.34$ & $9.41 \pm 0.27$ & $8.98 \pm 0.32$ & $8.91 \pm 0.23$ \\
\cline { 2 - 6 } & $90^{\text {th }}$ Day & $8.98 \pm 0.18$ & $9.41 \pm 0.37$ & $9.38 \pm 0.53$ & $9.35 \pm 0.37$ \\
\hline \multirow{2}{*}{$\mathbf{R B C}(\mathbf{x 1 0} / \boldsymbol{\mu L})$} & $0^{\text {th }}$ Day & $8.93 \pm 0.22$ & $8.86 \pm 0.32$ & $9.14 \pm 0.19$ & $8.6 \pm 0.31$ \\
\cline { 2 - 6 } & $90^{\text {th }}$ Day & $9.31 \pm 0.26$ & $9.04 \pm 0.27$ & $8.96 \pm 0.18$ & $9.05 \pm .18$ \\
\hline \multirow{2}{*}{$\mathbf{W B C}(\mathbf{x 1 0} / \boldsymbol{\mu} \mathbf{L})$} & 0th Day & $12.38 \pm 0.94$ & $12.4 \pm 0.46$ & $12.03 \pm 0.62$ & $10.56 \pm 0.38$ \\
\cline { 2 - 6 } & $90^{\text {th }}$ Day & $12.23 \pm 0.45$ & $14.31 \pm 1.43$ & $14.28 \pm 1.83$ & $13.08 \pm .71$ \\
\hline \multirow{2}{*}{$\mathbf{P C V}(\boldsymbol{\%})$} & $0^{\text {th }}$ Day & $31.25 \pm 0.59$ & $32.15 \pm 0.52$ & $31.15 \pm 0.58$ & $31.18 \pm 0.91$ \\
\cline { 2 - 6 } & $90^{\text {th }}$ Day & $29.91 \pm 0.68$ & $32.21 \pm 0.67$ & $31.20 \pm 1.34$ & $30.68 \pm 1.38$ \\
\hline
\end{tabular}

Table.2 Effect of probiotic, prebiotic and symbiotic supplementation on serum profiles in murrah calves

\begin{tabular}{|c|c|c|c|c|c|}
\hline Parameter & Days & C & T-1 & T- 2 & T-3 \\
\hline \multirow{2}{*}{ Glucose (mg/dL) } & $0^{\text {th }}$ Day & $79.87 \pm 3.63$ & $82.85 \pm 2.78$ & $76.08 \pm 2.61$ & $77.58 \pm 3.18$ \\
\hline & $90^{\text {th }}$ Day & $87.99 \pm 0.77$ & $88.28 \pm 1.16$ & $90.57 \pm 1.32$ & $89.51 \pm 1.66$ \\
\hline \multirow[t]{2}{*}{ Albumin (g/dL) } & $0^{\text {th }}$ Day & $3.23 \pm 0.13$ & $3.37 \pm 0.16$ & $2.72 \pm 0.15$ & $3.15 \pm 0.2$ \\
\hline & $90^{\text {th }}$ Day & $2.10 \pm 0.04$ & $2.19 \pm 0.06$ & $2.21 \pm 0.07$ & $2.11 \pm 0.04$ \\
\hline \multirow[t]{2}{*}{ Globulin (g/dL) } & $0^{\text {th }}$ Day & $1.69 \pm 0.12$ & $1.67 \pm 0.10$ & $1.94 \pm 0.15$ & $2.02 \pm 0.17$ \\
\hline & $90^{\text {th }}$ Day & $1.45 \pm 0.41$ & $1.39 \pm 0.09$ & $1.30 \pm 0.06$ & $1.37 \pm 0.05$ \\
\hline \multirow[t]{2}{*}{$(\mathrm{A} / \mathrm{G})$ ratio } & $0^{\text {th }}$ Day & $1.91 \pm 0.12$ & $2.01 \pm 0.10$ & $1.40 \pm 015$ & $1.48 \pm 0.17$ \\
\hline & $90^{\text {th }}$ Day & $1.44 \pm 0.04$ & $1.57 \pm 0.09$ & $1.7 \pm 0.06$ & $1.54 \pm 0.05$ \\
\hline \multirow[t]{2}{*}{ Totalprotein (g/dL) } & $0^{\text {th }}$ Day & $4.92 \pm 0.31$ & $5.04 \pm 0.23$ & $4.66 \pm 0.11$ & $5.02 \pm 0.46$ \\
\hline & $90^{\text {th }}$ Day & $3.55 \pm 0.06$ & $3.58 \pm 0.03$ & $3.51 \pm 0.07$ & $3.48 \pm 0.08$ \\
\hline \multirow[t]{2}{*}{ Cholesterol (mg/dl) } & $0^{\text {th }}$ Day & $90.17 \pm 7.23$ & $97.26 \pm 6.29$ & $96.06 \pm 8.34$ & $98.68 \pm 2.70$ \\
\hline & $90^{\text {th }}$ Day $^{*}$ & $110.32 \pm 1.31^{\mathrm{a}}$ & $80.78 \pm 1.76^{b}$ & $83.02 \pm 1.36^{b}$ & $75.64 \pm 0.26^{b}$ \\
\hline
\end{tabular}

Means with different superscripts in a row differ significantly $(* \mathrm{P}<0.05)$

Similarly Chaudhary et al., (2008) also observed no significant effect on globulin concentration when supplemented with direct fed microbial in crossbred cattle calves. However, contrary to our findings Singh et al., (2016) found an increase in serum globulin levels in the group fed with probiotic in Murrah buffalo calves. Singh et al., (2016a) also observed significant difference $(\mathrm{P}<0.01)$ in serum globulin levels between control and probiotic treatment group in Barbari kids.

\section{Albumin to globulin (A/G) ratio}

The effect of probiotic, prebiotic and synbiotic supplementation on albumin to globulin ratio is presented in Table 2. The present findings revealed that there was no significant difference in albumin to globulin ratio among the groups. In accordance to our findings Chaudhary et al., (2008) observed no significant effect on albumin to globulin ratio in crossbred calves supplemented with direct fed microbial. Galip (2006) also observed that the serum albumin to globulin ratio were not significantly modified in rams.

Contrary to our findings Singh et al., (2016) observed higher albumin to globulin ratio in probiotic supplemented groups when compared to control in Murrah buffalo calves. Similarly Singh et al., (2016a) found higher 
albumin to globulin ratio in supplemented groups in Barbari kids.

\section{Total protein}

The effect of probiotic, prebiotic and synbiotic supplementation on total protein is presented in Table 2. The results of the present study revealed that there was no significant difference in the total protein levels among the groups. In accordance to our findings Chaudhary et al., (2008) reported that the dietary supplementation of direct fed microbial had no significant effect on total protein in crossbred calves. This indicates that synbiotic supplementation did not affect utilization of dietary proteins or protein synthesis in liver.

Contrary to our findings Singh et al., (2016) observed higher total protein $(\mathrm{P}<0.05)$ in probiotic supplemented groups in Murrah buffalo claves. Singh et al., (2016a) also observed higher total protein level at monthly interval in probiotics supplemented group as compared to unsupplemented group in Barbari kids.

\section{Cholesterol}

The effect of probiotic, prebiotic and synbiotic supplementation on cholesterol in Murrah calves is represented in the Table 2. Statistical analysis revealed that there was no significant difference in the serum cholesterol up to $45^{\text {th }}$ day. From 60 to 90 days, there was significantly $(\mathrm{P}<0.05)$ lower levels of serum cholesterol was observed in probiotic, prebiotic and synbiotic supplemented groups. The results of present study are accordance with the findings of Dar et al., (2017) who indicated that probiotic (Lactobacillus acidophilus), prebiotic (MOS) and synbiotic supplementation were effective in reduction of serum cholesterol and triglycerides at $60^{\text {th }}$ and $90^{\text {th }}$ day. The reduction in serum cholesterol might be due to the assimilation of cholesterol into the Lactobacilli acidophilus cells (Drouault et al., 2002). Lower cholesterol values observed in synbiotic supplementation might be due to the production of short-chain fatty acids upon fermentation by probiotics in the presence of prebiotics as described by De Preter et al., (2007) in humans. The results are in accordance with the results of Al-Saiady (2010) who also reported a significant decrease in serum cholesterol levels in probiotic administered calves. Tang et al., (2005) reported significantly lower values of cholesterol in pigs that were supplemented with chitosan and galacto-mannan oligosaccharide as compared to control. Contrary with the present results, Takagi et al., (2011) reported significantly higher cholesterol concentration at $14^{\text {th }}$ day and $30^{\text {th }}$ day of experimental study in probiotic treated calves than control calf group. Frizzo et al., (2010) also reported no significant effect of feeding probiotic on serum total cholesterol levels in calves. No significant difference was observed in serum cholesterol levels between prebiotic group and control group in pigs (Rekiel et al., 2007).

The dietary supplementation of the above said probiotic, prebiotic and synbiotics have no effect on haematological and serum biochemical values in buffalo calves.

\section{References}

Abdel-Fattah, F. A., \& Fararh, K. M. 2009. Effect of dietary supplementation of probiotic, prebiotic and synbiotic on performance, carcass characteristics, blood picture and some biochemical parameters in broiler chickens. Benha Vet. Med. J, 20, 9-23.

Adams, M. C., Luo, J., Rayward, D., King, S., Gibson, R., \& Moghaddam, G. H. 2008. Selection of a novel direct-fed microbial to enhance weight gain in intensively reared calves. Animal Feed Science and 
Technology, 145(1-4), 41-52.

AFRC, R. F. 1989. Probiotics in man and animals. Journal of applied bacteriology, 66(5), 365-378.

Agazzi A, Tirloni E, Stella S, Maroccolo S, Ripamonti B, Bersani C and Savoini G 2014 Effects of species-specific probiotic addition to milk replacer on calf health and performance during the first month of life. Annals of Animal Science 14 (1): 101-115.

Al-Saiady, M. Y. 2010. Effect of probiotic bacteria on immunoglobulin $G$ concentration and other blood components of Newborn calves. Journal of Animal and Veterinary Advances, 9(3), 604-609.

Chaudhary, L. C., Sahoo, A., Agarwal, N., Kamra, D. N., \& Pathak, N. N. 2008. Effect of direct fed microbials on nutrient utilization, rumen fermentation, immune and growth response in crossbred cattle calves. Indian Journal of Animal Sciences (India).

Chen, Y. J., Son, K. S., Min, B. J., Cho, J. H., Kwon, O. S., \& Kim, I. H. 2005. Effects of dietary probiotic on growth performance, nutrients digestibility, blood characteristics and fecal noxious gas content in growing pigs. Asian-Australasian Journal of Animal Sciences, 18(10), 1464-1468.

Dar, A., Singh, S., Palod, J., Al Ain, K., Kumar, N., Khadda, B., \& Farooq, F. 2017. Effect of probiotic, prebiotic and Synbiotic on hematological parameters of crossbred calves. International Journal of Livestock Research, 7(4), 127-136.

Dimova, N., Baltadjieva, M., Karabashev, V., Laleva, S., Popova, Y., Slavova, P.,... \& Kalaydjiev, G. 2013. Effect of adding of probiotic "Zoovit" at feeding of lambs from breed synthetic population Bulgarian milk. Bulg J Agric Sci, 19, 98-101.

Drouault, S., Juste, C., Marteau, P., Renault, P., \& Corthier, G. 2002. Oral treatment with Lactococcus lactis expressing Staphylococcus hyicus lipase enhances lipid digestion in pigs with induced pancreatic insufficiency. Applied and Environmental Microbiology, 68(6), 3166-
3168.

El-Din, A. N. 2015. Milk production and some blood metabolite responses to yeast supplementation in early lactating holstein dairy cows. Egyptian J. Anim. Prod, 52(1), 11-17.

Frizzo, L. S., Soto, L. P., Zbrun, M. V., Bertozzi, E., Sequeira, G., Armesto, R. R., \& Rosmini, M. R. 2010. Lactic acid bacteria to improve growth performance in young calves fed milk replacer and spraydried whey powder. Animal Feed Science and Technology, 157(3-4), 159-167.

Galip, N. U. R. T. E. N. 2006. Effects of dietary Saccharomyces cerevisiae live yeast culture supplementation on ruminal digestion and protozoa count in rams fed with diets with low or high ratio forage/concentrate. Revue de Medecine Veterinaire, 157(12), 607-611.

Ghazanfar, S., Anjum, M. I., Azim, A., \& Ahmed, I. 2015. Effects of dietary supplementation of yeast (Saccharomyces cerevisiae) culture on growth performance,

blood parameters, nutrient digestibility and fecal flora of dairy heifers. J Anim Plant Sci, 25(25), 53-9.

Gujar, G. Study on the effects of probiotic and synbiotic supplementation on the production performance of Sahiwal cattle in arid region of Rajasthan (Doctoral dissertation, Rajasthan University of Veterinary and Animal Sciences, Bikaner).

Heinrichs, A. J., Jones, C. M., \& Heinrichs, B. S. 2003. Effects of mannan oligosaccharide or antibiotics in neonatal diets on health and growth of dairy calves. Journal of dairy science, 86(12), 4064-4069.

ICAR 2013 Nutrient Requirements of Cattle and Buffalo.Indian Council of Agricultural Research New Delhi.

Jin, L. Z., Ho, Y. W., Abdullah, N., \& Jalaludin, S. 1997. Probiotics in poultry: modes of action. World's Poultry Science Journal, 53(4), 351-368.

Kim, M. K., Lee, H. G., Park, J. A., Kang, S. K., \& Choi, Y. J. 2011. Effect of feeding direct-fed microbial as an alternative to antibiotics for the prophylaxis of calf 
diarrhea in Holstein calves. AsianAustralasian Journal of Animal Sciences, 24(5), 643-649.

Morrill, J. L., Morrill, J. M., Feyerherm, A. M., \& Laster, J. F. 1995. Plasma proteins and a probiotic as ingredients in milk replacer. Journal of dairy science, 78(4), 902-907.

Okamoto, Y., Inoue, A., Miyatake, K., Ogihara, K., Shigemasa, Y., \& Minami, S. 2003. Effects of chitin/chitosan and their oligomers/monomers on migrations of macrophages. Macromolecular Bioscience, 3(10), 587-590.

Rekiel, A. N. N. A., Wiecek, J., Bielecki, W. O. J. C. I. E. C. H., Gajewska, J. U. L. I. T. A., Cichowicz, M. A. R. Z. E. N. A., Kulisiewicz, J. Ó. Z. E. F., \& Beyga, K. A. R. O. L. I. N. A. 2007. Effect of addition of feed antibiotic flavomycin or prebiotic BIO-MOS on production results of fatteners, blood biochemical parameters, morphometric indices of intestine and composition of microflora. Arch. Tierz. Dummerstorf, 50, 172-180.

Resali, D. P. 2000 Recent trends in buffalo production in Nepal: A review, Buffalo News letter. Bulletin of the FAO InterRegional cooperative Research Network on Buffalo, Europe Near Estate 14: 6-10.

Rolfe, R. D. 2000. The role of probiotic cultures in the control of gastrointestinal health.

The Journal of nutrition, 130(2), 396S$402 \mathrm{~S}$.

Shrestha, S. K., \& Shrestha, N. P. 1998. Genetic improvement of buffalo. In Proc. First Nat. workshop on.

Silva, J. T. D., Bittar, C. M. M., \& Ferreira, L.
S. 2012. Evaluation of mannanoligosaccharides offered in milk replacers or calf starters and their effect on performance and rumen development of dairy calves. Revista Brasileira de Zootecnia, 41(3), 746-752.

Singh N., Aklank, J., Biswajit, R., \& Thakur, M. S. 2016b. Effect of dietary probiotic supplementation on biochemical profile of murrah buffalo calves. Indian Journal of Animal Production and Management, 32(1/2), 18-21.

Singh, S. P., Jain, A., Roy, B., \& Lakhani, G. P. 2016a. Effect of Saccharomyces cerevisiae and Lactobacillus acidophilus as Probiotics on Performance of Barbari kids. Journal of Animal Research, 6(1), 135-138.

SPSS version (15.01) 2006, Chicago. IL: SPSS Inc. 2006.

Takagi, M., Hasunuma, H., Matsumoto, D., Obi, T., Takase, K., Ohtani, M.,... \& Tshering, C. 2011. Effects of daily oral administration of difructose anhydride III on health status, blood parameters and faecal shedding of coliform bacteria of Japanese Black calves during the preweaning period. Animal Nutrition and Feed Technology, 11(2), 147-148.

Tang, Z. R., Yin, Y. L., Nyachoti, C. M., Huang, R. L., Li, T. J., Yang, C.,... \& Xing, J. J. 2005. Effect of dietary supplementation of chitosan and galactomannan-oligosaccharide on serum parameters and the insulin-like growth factor-I mRNA expression in early-weaned piglets. Domestic Animal Endocrinology, 28(4), 430-441.

\section{How to cite this article:}

Sri Lekha, M., Ch. Venkata Seshaiah, P. Ashalatha and Raja Kishore, K. 2021. Effect of Probiotic, Prebiotic and Synbiotic Supplementation on Haematological and Serum Biochemical Profiles in Murrah Buffalo Calves. Int.J.Curr.Microbiol.App.Sci. 10(05): 272-279. doi: https://doi.org/10.20546/ijcmas.2021.1005.034 